\title{
COMMUNITY-ACQUIRED BACTERIAL MENINGITIS
}

Meningitis is an inflammation of the bacterial infections that can lead to meningitis are caused by Streptococcus pneumoniae and Neisseria meningitidis. Meningitis is a medical emergency that requires immediate treatment.

\section{DIAGNOSIS}

Classic symptoms of meningitis are neck stiffness, fever and altered mental status; however, not all patients show them. If bacterial meningitis cannot be excluded, a lumbar puncture should be performed, if safe. A positive cerebrospinal fluid (CSF) culture typically shows a high density of leukocytes - a sign that the host inflammatory and immune response has been triggered by bacterial invasion and proliferation in the CSF.

High leukocyte density in the CSF might not always be present, especially in patients with compromised immune systems or in those who received antibiotics before lumbar puncture; alternative diagnostic tests might be required.

\section{PREVENTION}

The introduction of vaccines covering several bacterial types that are implicated in meningitis has led to a reduction in the global incidence. Reduced transmission

also protects

individuals who

have not received
a vaccine or have a response to it, in particular, infants and the elderly

(herd protection). meninges lining the brain. Common

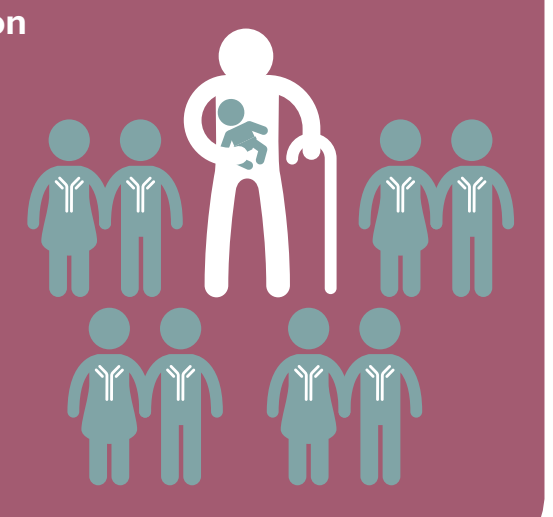

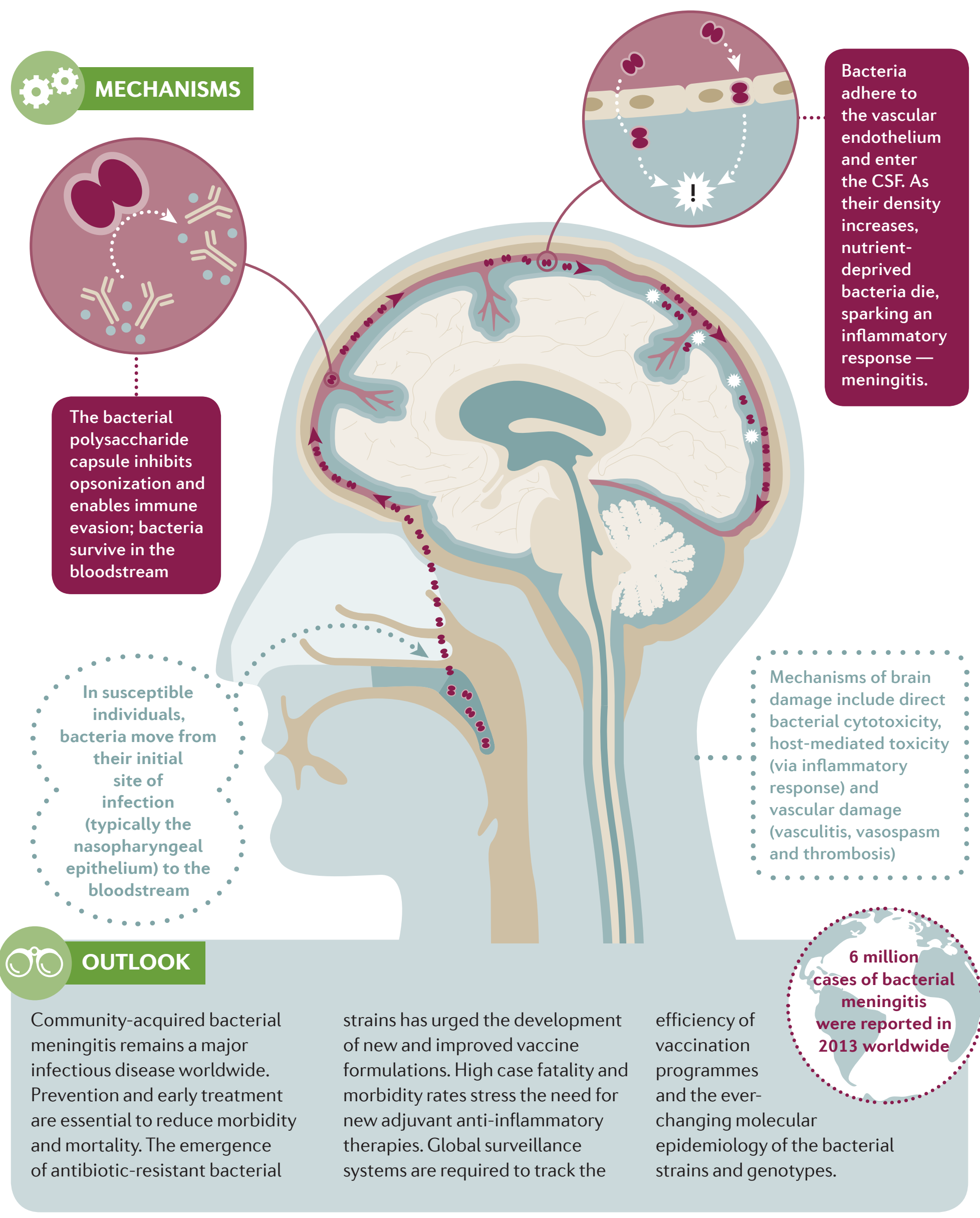

Written by Lucia Brunello; designed by Neil Smith and Laura Marshall

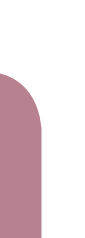

